\title{
District heating and power generation based flue gas waste heat recovery $y^{\S}$
}

\author{
Caglar Karaoglu', Arif Ozbek ${ }^{2 *}$ \\ ${ }^{1}$ Cukurova University, Institute of Natural and Applied Sciences, Mechanical Engineering Department, Adana, Turkey \\ ${ }^{2}$ Cukurova University, Ceyhan Engineering Faculty, Mechanical Engineering Department, Adana, Turkey
}

\begin{abstract}
In this study, integration of appropriate renewable methods are going to be applied on conventional coal fired steam power plant which has $660 \mathrm{MW}$ full load capacity and including 4 Turbines (1 HP, $1 \mathrm{IP}$ and $2 \mathrm{LP}$ ), one Benson type boiler and having multi pre heater stages for each unit. Steam parameters are 177 Bar and 541 ${ }^{\circ} \mathrm{C}$ super-heater section and 50 bar $539^{\circ} \mathrm{C}$ for re-heater section. Primary fuel is coal except for startup and shut down operations. It is aimed by retrofitting some renewable energy methods on existing power plant, thus eliminating conventional type power plants adverse effects on thermodynamically, environmental and economic issues.

One of the most important issue of conventional steam power plant operation is waste heat recovery management. A widespread techniques has been developed on this topic. It's possible to handle low grade heat by considering thermodynamic and environmental facts and also dealing with restrictions and opportunities after fulfilled feasibility study. In this study, it is being proposed waste heat recovery by combining OrganicRankine Cycle (ORC) with steam-Rankine cycle at available section. Brief summary of operation is ORC takes place after regenerative air preheater section and the target is to utilize waste heat of flue gas either via district heating or power generation up to few MW values. Depending upon the calculation and results additional modifications can further be needed as well.
\end{abstract}

Keywords: Waste heat recovery, flue gas, steam power plant

\section{INTRODUCTION}

Energy is the power and vital part of life. In the future, we must have a sustainable, affordable and environment friendly energy supply. Conventional fossil energy sources will be replaced by renewable sources, gradually. Renewable technologies are considered as clean sources of energy and optimal use of these resources minimize environmental impacts, produce minimum secondary wastes and are sustainable based on current and future economic and social needs. [1].

A major challenge for the future electric grid is to integrate renewable power sources such as solar, wind and biomass [2]. Such sources are variable and intermittent, unlike traditional sources that provide a controllable, steady stream of power. Instead of fully replacing renewable by conventional systems, it's better to implement partial integration of renewable methods on such conventional power plants already in operation.

Renewable energy systems are increasingly being used for electricity generation, either at small-scale decentralized systems with capacity in the $\mathrm{kW}$ scale or even medium-scale systems (often called utility-scale) with capacity of afew MW. However, the large-scale systems with capacity of some hundreds of MW are still using conventional technologies based on fossil fuels.

One of the most important disadvantages of conventional technologies is the environmental impact. The combustion of fossil fuels leads to the inevitable production of carbon dioxide $\left(\mathrm{CO}_{2}\right)$, while most of the times harmful emissions are produced, such as carbon monoxide (CO), nitrogen oxides (NOX), sulfur oxides (SOX), unburned hydrocarbons (HC), and solid particles. Another critical disadvantage of conventional technologies is that they need continuous fuel supply to operate, which contributes to the operating costs.

On the other hand, renewable energy technologies do not require any fossil fuel during normal operation. Their operation is based on the exploitation of natural resources, such as the sun and wind, having relatively lower operating costs,

\footnotetext{
${ }^{*}$ Corresponding authour

Email: arozbek@cu.edu.tr (A. Özbek)

$\S$ This paper was presented in the IMSEC-2016
} 
although they still require some maintenance. The most important disadvantage of renewable energy technologies is the fluctuation of their power output [5].

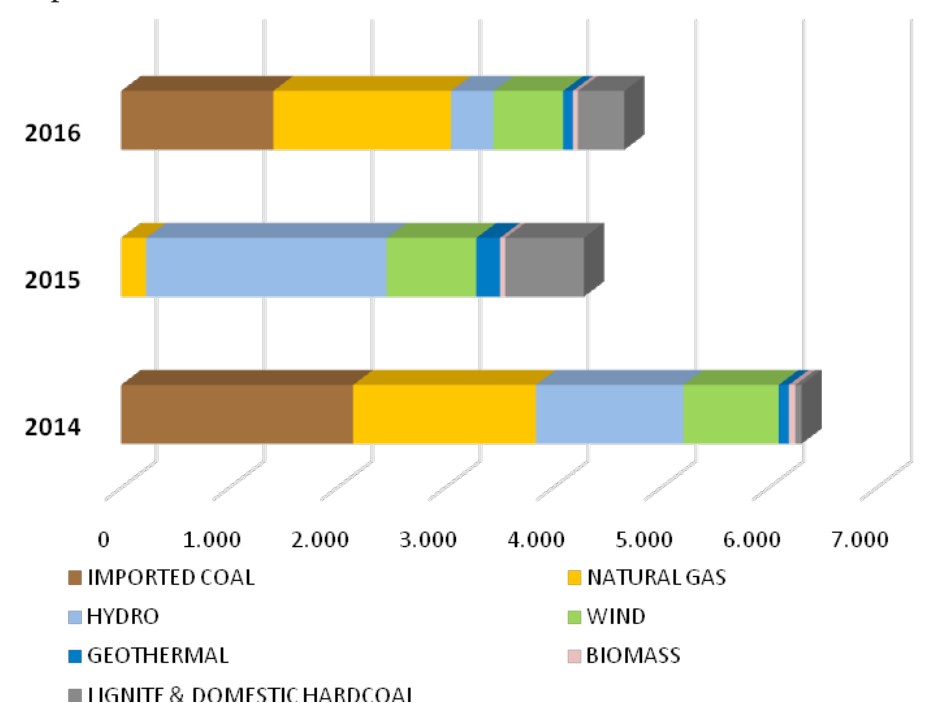

Figure 1: Additional Installed Capacity by years

It is generally expected that coal will continue to play a key role in the future energy mix as it is the most abundant and cheapest fossil fuel source.Such solid fossil fuels are combusted insteam power plants, where the power cycle is based on the steam-Rankine thermodynamic cycle, using a steam turbine.

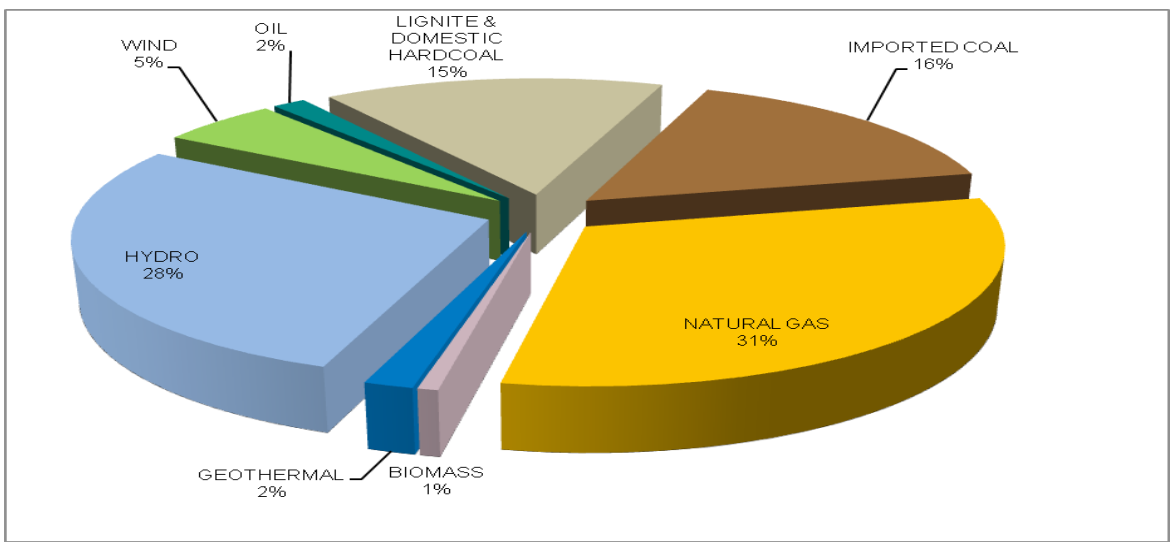

Figure 2: Electricity Generation Distribution Depend on Energy Sources (2016)

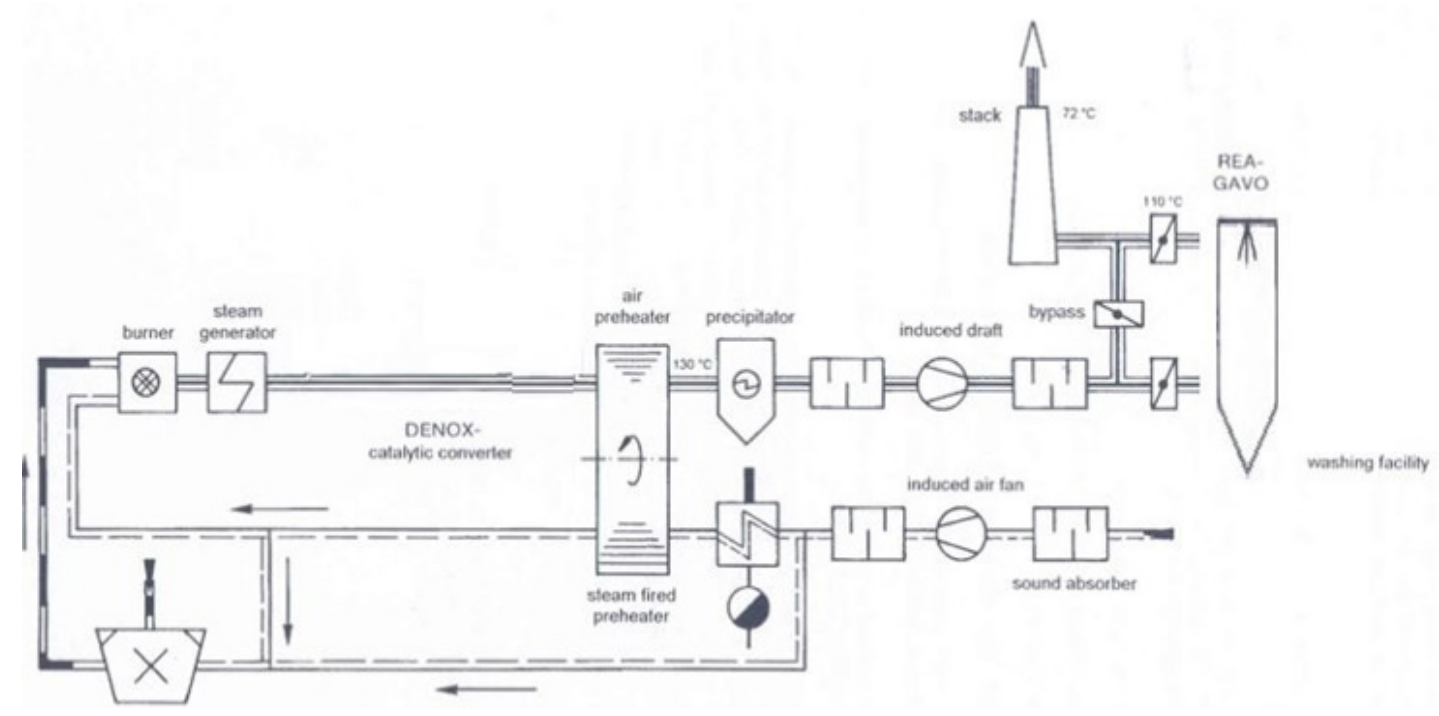

Figure 2: A path of Air/Flue-gas 
Additionally, pulverized coal firing system, integrated with its components, in the steam generator (boiler) is to provide through the combustion of certain bituminous coals the necessary thermal energy for the generation of steam which in turn is required for driving the downstream turbine with downstream generator for power generation. Flue gases leaving the boiler combustion chamber pass over the convection banks of the super-heaters, re-heaters and then enter regenerative air heater. There the gases exchange their thermal energy with the primary and secondary air. The temperature of the gas entering the air heater is reduced from about $400{ }^{\circ} \mathrm{C}$ to $150^{\circ} \mathrm{C}$. The cooled gases then pass to electrostatic precipitator where most of the dust is removed. Via induced draft fan, the cleaned gases then pass to the FGD plant for desulfurization and then to atmosphere via the stack [4].

It is possible to see several studies that deal with renewable energy integration to conventional systems related to thermodynamic analysis.

\subsection{Literature Survey}

Gang Xu et al. (2014) studied integration of waste heat recovery system on flue gas path. To achieve extra work, installed low temperature economizer after ESP takes place. Exergy analysis and economic analysis have been done and discussed on results [6].

C. Li et al. (2016) investigated on generated waste heat quantities during industrial production. In order to maximize net power output, an optimal combination of cycle configuration, fluid and cycle parameters under different heat source condition, the following researches have been performed. To sum up, results indicate that the regenerative organic trans-critical cycle produces the maximum power output at source temperatures up to about $500{ }^{\circ} \mathrm{C}$, and different optimum working fluids are obtained under different heat source temperature [7].

Chengyu Li et al. (2016) has been studied for waste heat recovery from flue gas in a wide range temperature. The study also dealing with optimum relationship between selected fluid and heat source in order to achieve better thermal efficiency. Evaluation, optimization comparison of many cycles has been evaluated.

Xiaoqu Han et al. (2016) studied on flue gas waste heat recovery method by extracting water from high moisture lignite coal thus yielding increase of boiler efficiency. Energy saving potential has also been evaluated. To achieve this, different options take into consideration like economizer or spray tower. Thermodynamic and economic performance of system are investigated for each scheme [8].

Jiaxi Xia et al. (2016) performed thermo - economical analysis of combined system which is named combined cooling and power system for engine waste heat recovery. Vital part of the system thermodynamically based were studied. Exergo-economic evaluation is another branch of this study. Via the single-objective optimization, the lowest average cost per unit of exergy product for the overall system is obtained [9].

Navid Nazaria et al. (2016) proposed multi objective optimization of combined steam\& ORC based on exergy and exergo-economic analysis of waste heat recovery application. Combined cycle has been performed in terms of exergo-economic and exergy efficiency. Total product cost rate and exergy efficiency were cornerstone of this study. Three different type fluid selection has been monitored to perform system characteristic as well [10].

Zhenying Wang et al. (2016) has been presented evaluation of flue gas waste heat and water recovery from a fossil fuel boilers. Several parameters has been studied like efficient heat and water recovery for various kinds of fossil fuel boilers, heat recovery dependency parameters like moisture content [11].

Xiling Zhao et al. (2016) presented another waste heat recovery method, known peak shaving heat pump. This study consist of improving transmission network and distribution capacity, Also study proposed by heating capacity, and reduced heating energy consumption. As such, the proposed system is advantageous in terms of energy saving, emission reduction, and economic benefits [12].

\section{MATERIAL AND METHOD}

In this study, integration of appropriate renewable methods are going to be applied on conventional coal fired steam power plant which has $660 \mathrm{MW}$ full load capacity and including 4 Turbines (1 HP,1 IP and $2 \mathrm{LP}$ ), one Benson type boiler and having multi pre heater stages for each unit. Steam parameters are 177 bar and $541^{\circ} \mathrm{C}$ super-heater section and $50 \mathrm{bar} 539^{\circ} \mathrm{C}$ for re-heater section. Primary fuel is coal except for start up and shut down operations. It is aimed by retrofitting some renewable energy methods on existing power plant, thus eliminating conventional type power plants adverse effects on thermodynamically, environmental and economic issues.

One of the most important issue of conventional steam power plant operation is waste heat recovery management. A widespread techniques has been developed on this topic. It's possible to handle low grade heat by considering thermodynamic and environmental facts and also dealing with restrictions and opportunities after fulfilled feasibility study. In 
this study, it is being proposed waste heat recovery by combining Organic-Rankine cycle with steam-Rankine cycle at available section. Brief summary of operation is ORC takes place after regenerative air preheater section and the target is to utilize waste heat of flue gas either via heating or power generation up to few MW values. Depending upon the calculation and results additional modifications can further be needed as well.

However, the aim of an ORC machine is the power generation and as secondary purpose cogeneration or tri generation with hot water production for heating/cooling.

As seen below figure waste heat recovery is the highest temperature recovery ORC application. The higher temperature available the higher conversion capability means the higher efficiency of cycle thus reduction of waste energy and heat.

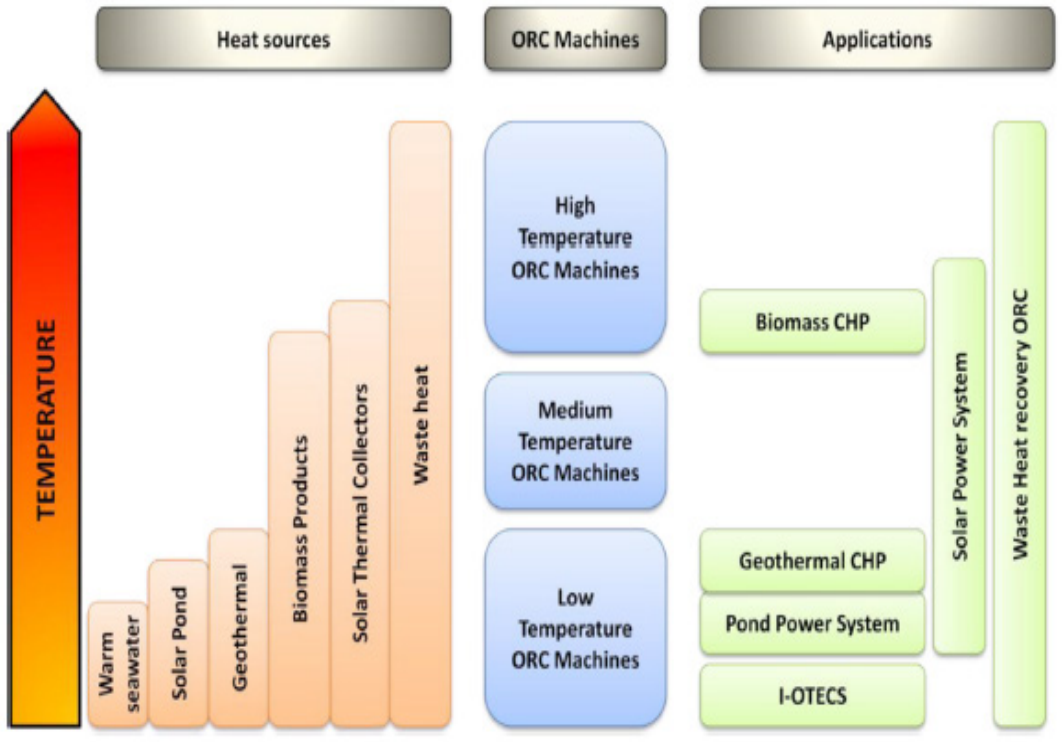

Figure 3: ORC Applications

\subsection{District Heating \& Internal Process Heating Based Flue gas Heat Recovery}

The temperature of the flue gas upstream of the absorbers is around $140-150{ }^{\circ} \mathrm{C}$ and the volumetric flow is $-760 \mathrm{~m}^{3} / \mathrm{s}$. Therefore there is considerable heat potential, if it can be utilised in an appropriate and efficient way. It is assumed that the temperature at the outlet of the absorber (inlet of the stack) doesn't change or change marginally because of water / steam saturation effect. Indeed if the flue gas inlet temperature of the absorber is lower, then less heat energy is provided into the FGD system and less amount of water will be vaporized.

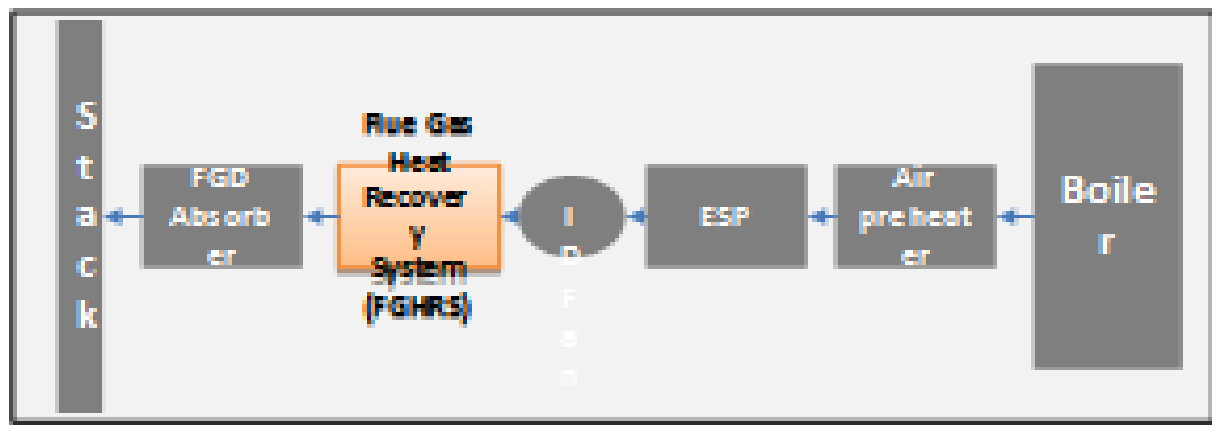

Figure 4: Flue gas heat recovery system

As it known that steam power plant have waste energy, it should be decreased to enhance efficiency so ORC will be placed out of boiler to recover energy, proper fluid selection which is used as refrigerant in ORC, is very important section while dealing with relatively lower energy conversion studies. Although there is considerable heat potential, it can only be of feasible usage if there is a continuous consumer. Evaluation both internal and external consumer options will also be considered in this study. Internal options can be accounted first feed water preheating or to heat primary air that will increase combustion efficiency in the air/flue gas system. Besides, it is possible to heat clean gas in the stack in order to prevent visible plume and it can also help to create additional vacuum in the stack which may help IDF. 


\subsection{Power Generation Based Flue gas Heat Recovery}

In this chapter, it is going to be evaluated a potential of residual flue gas temperature which is around $400{ }^{\circ} \mathrm{C}$ medium temperature before air heater section. In order to utilize that great potential waste heat after combustion process, regenerative air pre-heater has been settled down to handle heat transfer between flue gas and fresh air. Normal operation conditions described as follows:

Multi flow designs like tri and quart sector shaped air heater allow preheating of primary and secondary air in one air heater. Specially with respect to the high pressure difference between primary air and flue gas double seal system minimize leakage of primary air into the flue gas.

Instead using regenerative air pre heater alternative recovery method can be implemented at available flue gas path. Power generation based ORC integration is main idea of this study that is proposed converting a great waste heat of flue gas into electric generation via ORC. A proper fluid selection, ORC equipment (ORC pump, evaporator, turbine, condenser), exergo - economic analysis, data table, graphs are main study cases. Thus depending on cycle efficiency up to a few MW can be obtained by flue gas waste heat recovery.

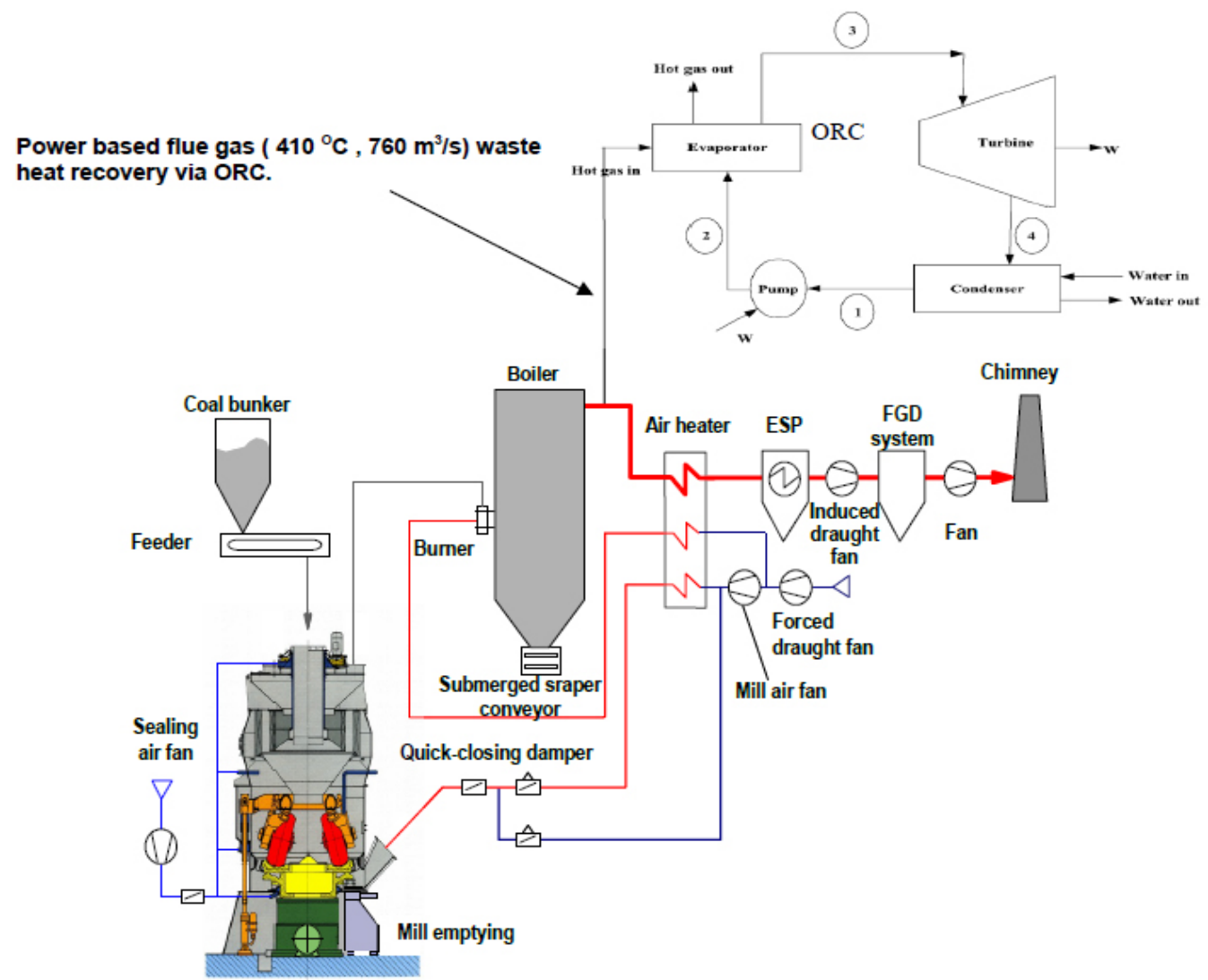

Figure 4 : Air / Flue gas system integration with power generation based flue gas waste heat recovery via ORC

\section{RESULT AND DISCUSSION}

In this chapter, it is going to be discussed the expectations on waste heat recovery benefits, expenditures and losses, heat gains and comparison between conventional type systems and renewable integrated systems. All parameters needed to calculate thermodynamic laws which are actually first law of thermodynamic and second law of thermodynamic, is taken from coal fired steam power plant. Those are mainly flow rate of flue gas, temperature of flue gas, pressure of flue gas and whatsoever needed. Basic expectations are described as follows:

Higher efficiency

Reduction wastes

Lower operating costs

Decreasing adverse environmental effect of main fuel ( coal)

The calculations and discussion topics are going to be performed are below:

Energy analysis : First Law of Thermodynamic 
Exergy analysis : Second Law of Thermodynamic

Exergo economic analysis: Cost analysis of exergy loss $\&$ annual saving, investment options for necessary part.

Environmental analysis : Impacts in emission $\left(\mathrm{CO}_{2}\right.$ emission $)$

To sum up, one of the weaken part of conventional type power plant is waste heat regeneration that exist on flue gas path. By using ORC combined with Steam Rankine Cycle, total losses will be minimized via integrating waste heat recovery system on flue gas path thereby energy conversion takes more efficiently into either heating or power based theory. Depending upon the consumer opportunities, heating based project is going to be justified while decision procedure. Consumer options are seem to be external as district heating or internal options as feed water preheating, combustion air preheating or clean gas preheating.

\section{REFERENCE LIST}

[1] NREL. Dollars From Sense: The Economic Benefits of Renewable Energy Retrieved. November 242013.

[2] United States Senate, One Hundred Eleventh Congress. First Session to Receive Testimony on a Majority Staff Draft for a Renewable Electricity Standard Proposal, Hearing before the Committee on Energy and Natural Resources; U.S. Government Printing Office; February 2009.

[3] Froese R.E., Shonnard D.R., Miller C.A., Koers K.P. and Johnson D.M. (2010). An evaluation of greenhouse gas mitigation options for coal-fired power plants in the US Great Lakes States. Biomass and Bioenergy vol. 34 no. 3, p. 251-262.

[4] Babcock Operating/Maintanance Manual System Description for training Steam Generator.

[5] Kosmadakis G., Manolakos D., Papadakis G. (2011). Simulation and economic analysis of a CPV/thermal system coupled with an organic Rankine cycle for increased power generation. Solar Energy, vol. 85 no. 2, p. 308-324.

[6] Xu G., Huang S.W. and Yang Y.P. (2013). Techno-economic analysis and optimization of the heat recovery of utility boiler flue gas; Applied Energy, vol. 112, p. 907-917.

[7] Chengyu L. and Huaixin W. (2016). Power cycles for waste heat recovery from medium to high temperature. Applied Energy, vol. 180 , p. $707-721$.

[8] Xiaoqu H., Junjie Y., Sotirios K. , Ming L., Kakaras E. and Feng X. (2016). Water extraction from high moisture lignite by means of efficient integration of waste heat and water recovery technologies with flue gas pre-drying system. Applied Thermal Engineering, vol.110, pp.442-456.

[9] Jiaxi X., Jiangfeng W., Juwei L., Pan Z. and Yiping D. (2016). Thermo-economic analysis and optimization of a combined cooling and power (CCP) system for engine waste heat recovery. Energy Conversion and Management, vol. 128, p. 303-316.

[10] Navid N., Parisa H. and Soheil P. (2016). Multi-objective optimization of a combined steam-organic Rankine cycle based on exergy and exergo-economic analysis for waste heat recovery application. Energy Conversion and Management, vol. 127, p. $366-379$.

[11] Zhenying W., Xiaoyue Z., Zhen L. (2016). Evaluation of a flue gas driven open absorption system for heat and water recovery from fossil fuel boilers. Energy Conversion and Management, vol. 128, p. 57-65.

[12] Xiling Z., Lin F., Xiaoyin W., Tao S., Jingyi W. and Shigang Z. (2016). Flue gas recovery system for natural gas combined heat and power plant with distributed peak-shaving heat pumps. Applied Thermal Engineering, vol. 111, p. 599-607. 